\title{
ULTRA-ESTRUTURA DE GLÂNDULAS ABDOMINAIS TEGUMENTARES EM OXAEA FLAVESCENS (HYMENOPTERA, ANDRENIDAE, OXAEINAE)
}

\section{Adriane Cristina Guerino ${ }^{1,2}$ Carminda da Cruz-Landim ${ }^{1}$}

\begin{abstract}
ULTRASTRUCTURE OF ABDOMINAL TEGUMENTAR GLANDS IN OXAEA FLAVESCENS (HYMENOPTERA, ANDRENIDAE, OXAEINAE). The sternal glands of the abdomen of Oxaea flavescens (Klug, 1807) consist of class III glandular cells around a reservoir constituted by branched folds of the intersegmental membrane of segments III, IV and V. The gland cells are rich in rough endoplasmic reticulum and produce a secretion with mucous aspect. The treatment with oxidated osmium and ruthenium red showed numerous Golgi regions in the cell and carbohydrates absorption from the haemolymph, respectively. The high degree of development of the glands suggests an important function to the species, although still unknown.
\end{abstract}

KEYWORDS. Tegumentary glands, exocrine glands, sternal glands, Oxaea.

\section{INTRODUÇÃO}

As abelhas possuem no abdômen glândulas exócrinas tegumentares, as glândulas tergais, distribuídas dorsalmente e as glândulas esternais ventralmente (SNODGRASS, 1956; CRUZ-LANDIM, 1963, 1996). A maioria destas glândulas é constituída por células da classe III, segundo classificação de NoIROT \& QUENNEDEY (1991) e, provavelmente, produzem feromônios (Wilson, 1963; Velthuis, 1970; Blum \& BRAND, 1972) sendo importantes em processos tais como comunicação, acasalamento, defesa e delimitação de territórios das espécies.

Oxaea flavescens (Klug, 1807) possui glândulas desse tipo, muito desenvolvidas, localizadas nos esternitos III, IV e V. Na maioria das espécies, as glândulas da classe III não possuem reservatório e, em $O$. flavescens, as membranas intersegmentais formam invaginações ramificadas, onde a secreção é acumulada. Estas glândulas são particulares por sua secreção reagir positivamente ao tratamento pelo ácido periódico-Schiff e corarse com o azul de bromofenol, o que indica uma natureza glico-protéica (GUERINo \& CRUZLANDIM, 1999). Relata-se a morfologia e ultra-estrutura dessas glândulas.

1. Departamento de Biologia, Instituto de Biociências, Universidade Estadual Paulista (UNESP), 13506-900, Rio Claro, São Paulo, Brasil. (aguerino@ms.rc.unesp.br)

2. Bolsista CNPq-PIBIC. 


\section{MATERIAL E MÉTODOS}

Fêmeas adultas de Oxaea flavescens foram obtidas através de coletas no campus da Universidade Estadual Paulista, em Rio Claro, São Paulo.

As glândulas foram, após dissecadas, fixadas em Karnovsky, desidratadas em ponto crítico e fotografadas em microscópio eletrônico de varredura (MEV). Para observação ao microscópio eletrônico de transmissão (MET), as glândulas foram fixadas em glutaraldeído a 2,5\% em tampão cacodilato de sódio $0,1 \mathrm{M}, \mathrm{pH} 7,2$, pós-fixadas em tetróxido de ósmio a $1 \%$ no mesmo tampão, contrastadas durante 6 horas em acetato de uranila a $2 \%$ e em álcool etílico a $10 \%$ no escuro. A seguir, desidratadas em uma série de soluções de acetonas de concentrações crescentes e incluídas em Epon araldite. As secções ultrafinas foram contrastadas com citrato de chumbo, examinadas e fotografadas em MET. Na fixação de algumas glândulas juntou-se aos fixadores, tanto glutaraldeído como tetróxido de ósmio, $0,05 \%$ de vermelho de rutênio, para evidenciar polissacarídeos. Para salientar elementos do Complexo de Golgi, as glândulas foram fixadas em tetróxido de ósmio oxidado a $2 \%$ em tampão cacodilato de sódio a $0,1 \mathrm{M}$ a $40^{\circ} \mathrm{C}$ por 24 horas. Após esse período, o fixador foi substituído por uma solução de tetróxido de ósmio não-oxidado a $1 \%$ e deixado por mais 24 horas a $40^{\circ} \mathrm{C}$. Após lavado, o material permaneceu em acetato de uranila a $0,5 \%$ por duas horas em temperatura ambiente e posteriormente foi incluído em resina pelo processo usual.

\section{RESULTADOS E DISCUSSÃO}

As glândulas tegumentares abdominais de Oxaea flavescens são constituídas por três pares de expansões laterais das membranas intersegmentares dos esternitos III, IV $\mathrm{e} \mathrm{V}$, as quais se ligam às células glandulares da classe III (fig. 1). Ao MEV, as glândulas aparecem como estruturas de contornos irregulares, formadas por uma porção central, a partir da qual originam-se projeções digitiformes. A superfície externa é de textura lisa, mas apresenta saliências arredondadas que correspondem às células secretoras. Alguns ramos traqueais são vistos sobre essa superfície, os quais podem penetrar por orifícios, entre as células, para o interior das glândulas (fig. 2). Diferentemente da maioria das glândulas abdominais formadas por células da classe III, nestas as células ficam justapostas com pequena aderência entre elas, constituindo uma espécie de epitélio secretor ao redor das invaginações da membrana intersegmental, que formam, desta forma, um reservatório central (figs. 1,3). Cada célula continua provida do seu próprio canalículo excretor que a liga ao reservatório. O reservatório é constituído por uma camada de células baixas, contínuas com a epiderme, recobertas na face luminal por cutícula, contínua com a cutícula do exoesqueleto (fig. 3). As células glandulares revestem o reservatório liberando a secreção para o seu interior, através de seus canalículos excretores. A membrana intersegmental passa, então, a constituir uma íntima (fig. 3). A secreção é estocada no reservatório antes de ser eliminada para o exterior (GuERINo \& CRUZ-LANDIM, 1999). Em outras abelhas, onde glândulas com localização semelhante não têm reservatório, a secreção é mantida no interior das células glandulares e eliminada diretamente para o exterior pelo canalículo excretor. A presença de um reservatório permite acumular secreção em larga escala, para ser usada quando requerido pela biologia da espécie. A função da secreção não é conhecida, mas o fato de existirem três pares destas glândulas com grande quantidade de células secretoras em cada uma delas, sugere papel importante para a espécie. A própria formação do reservatório, com lúmen ramificado, indica um aumento de superfície para ligação de maior número de células secretoras e maior espaço para estocar secreção.

A ultra-estrutura das células glandulares revelou retículo endoplasmático granular

Iheringia, Sér. Zool., Porto Alegre, 92(4):37-45, 30 de dezembro 2002 

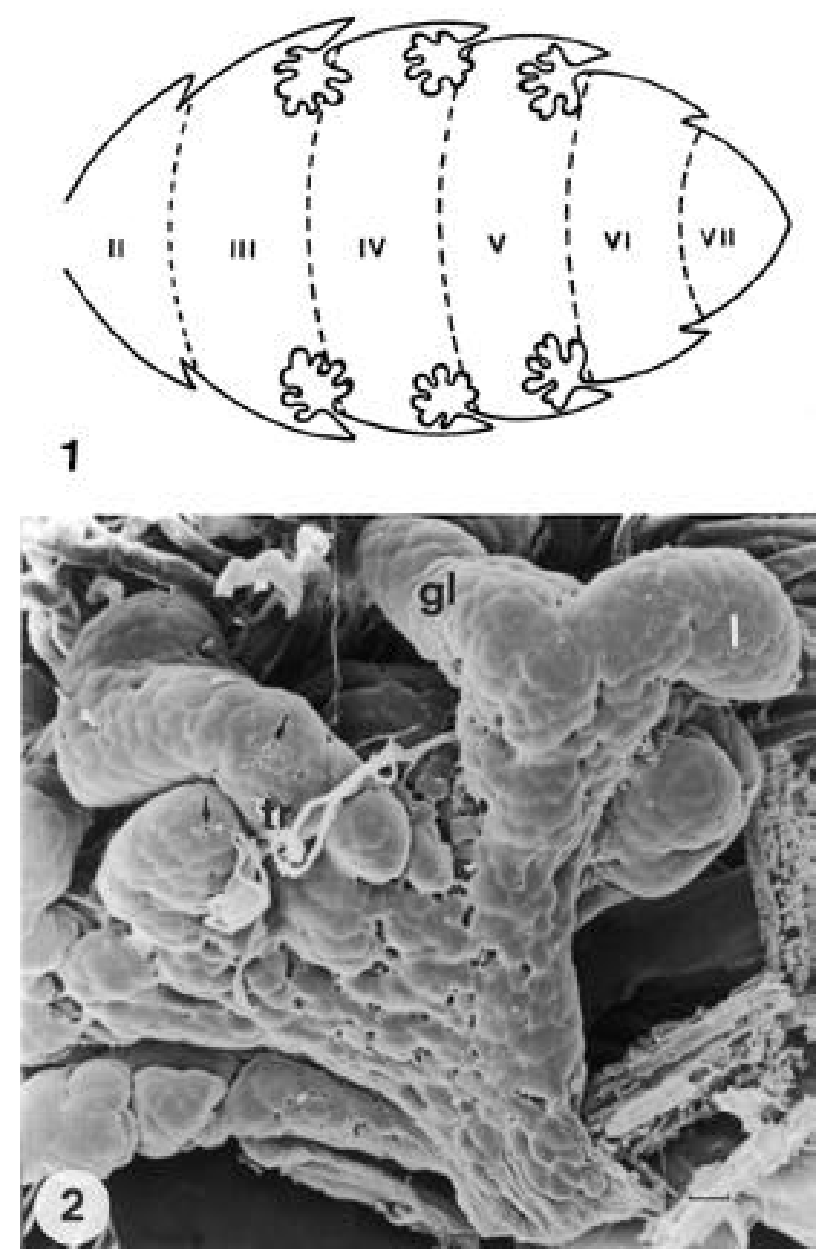

Figs. 1, 2. Oxaea flavescens, glândulas abdominais esternais: 1, esquema da localização; 2, glândulas esternais com vários lóbulos, mostrando aberturas (setas), por onde penetram traquéias (MEV) (gl, glândulas esternais; 1, lóbulos; tr, traquéias). Escala, $10 \mu \mathrm{m}$.

formado por ilhas de cisternas empilhadas, com lúmen estreito e bordas bem dilatadas, separadas por regiões livres de organelas, aparentemente contendo secreção de substâncias protéicas de aspecto mucoso (figs. 4, 5). Em algumas células, o retículo ao redor da secreção apresenta-se totalmente vesicular, com a luz contendo material semelhante ao dos glóbulos secretores maiores, os quais também são rodeados por membranas do retículo granular (fig. 6). Este aspecto leva a supor que a secreção se acumula no interior do retículo, principalmente nas bordas das cisternas, cuja luz vai se dilatando e formando vesículas cada vez maiores, as quais acabam por se destacar destas. Os núcleos das células são grandes e possuem contornos irregulares, além de 

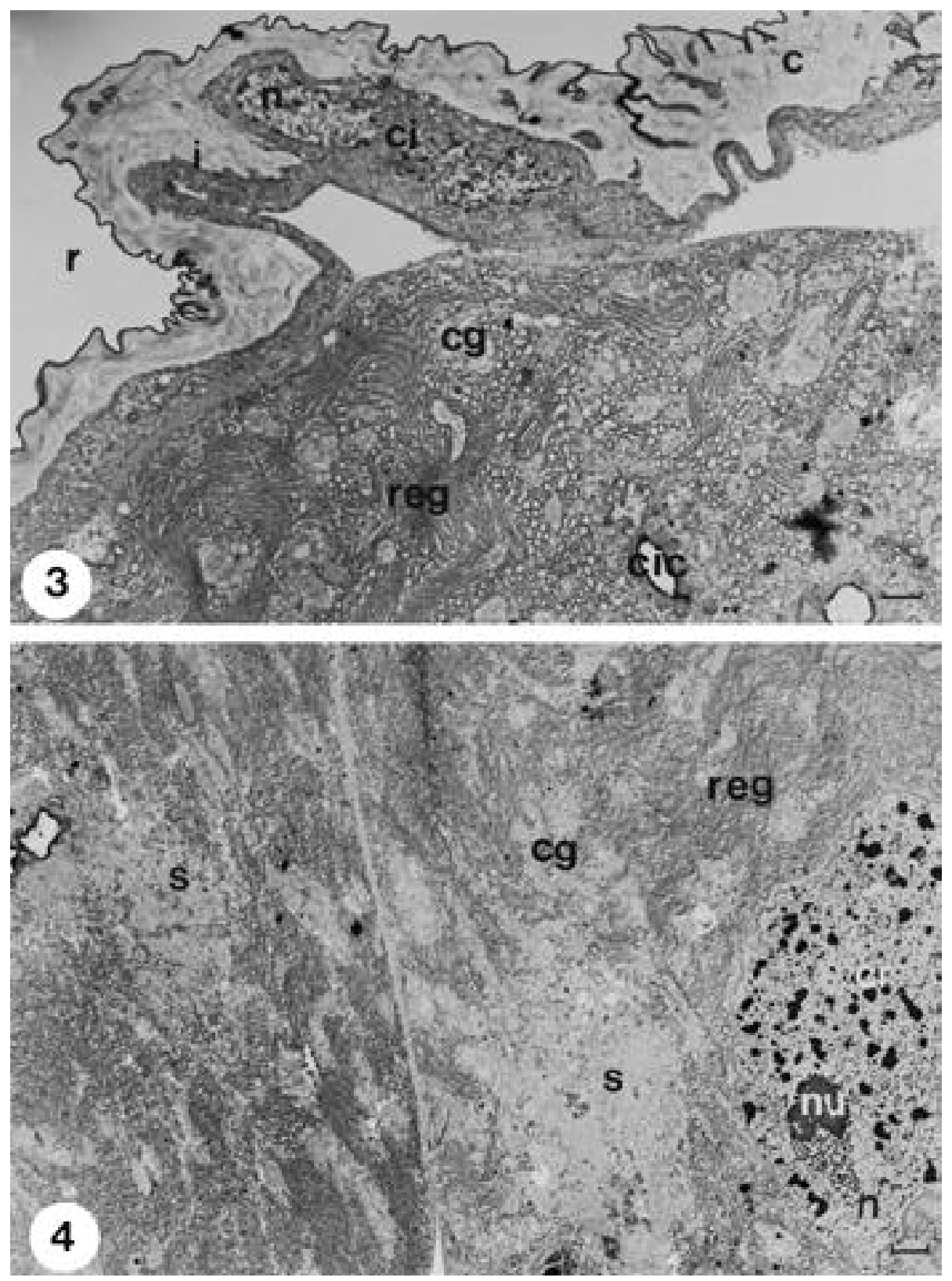

Figs. 3, 4. Oxaea flavescens, glândulas abdominais esternais (MET): 3, íntima que reveste o reservatório; 4, células glandulares (c, cutícula; cg, célula glandular; ci, célula da íntima; cic, canalículo intracelular; cr, heterocromatina; i, íntima; n, núcleo; nu, nucléolo; s, regiões de acúmulo de secreção; r, reservatório; reg, retículo endoplasmático granular). Escala, $1 \mu \mathrm{m}$.

Iheringia, Sér. Zool., Porto Alegre, 92(4):37-45, 30 de dezembro 2002 

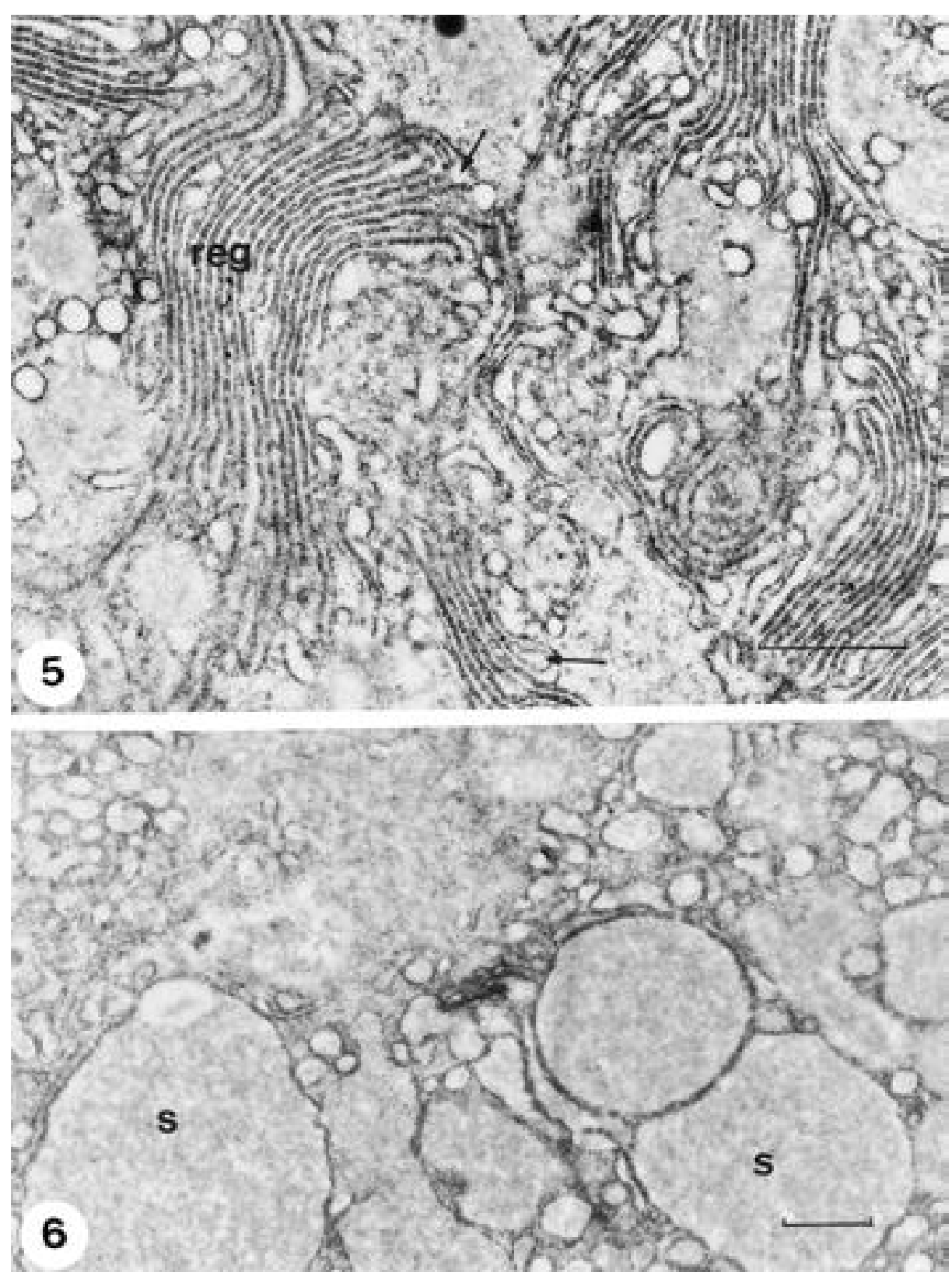

Figs. 5, 6. Oxaea flavescens, glândulas abdominais esternais (MET): 5, ilhas de cisternas do retículo endoplasmático granular; 6, vesículas contendo secreção, envoltas por membranas contendo ribossomos na superfície (reg, retículo endoplasmático granular; s, secreção; setas, extremidades dilatadas das cisternas). Escala, $1 \mu \mathrm{m}$. 

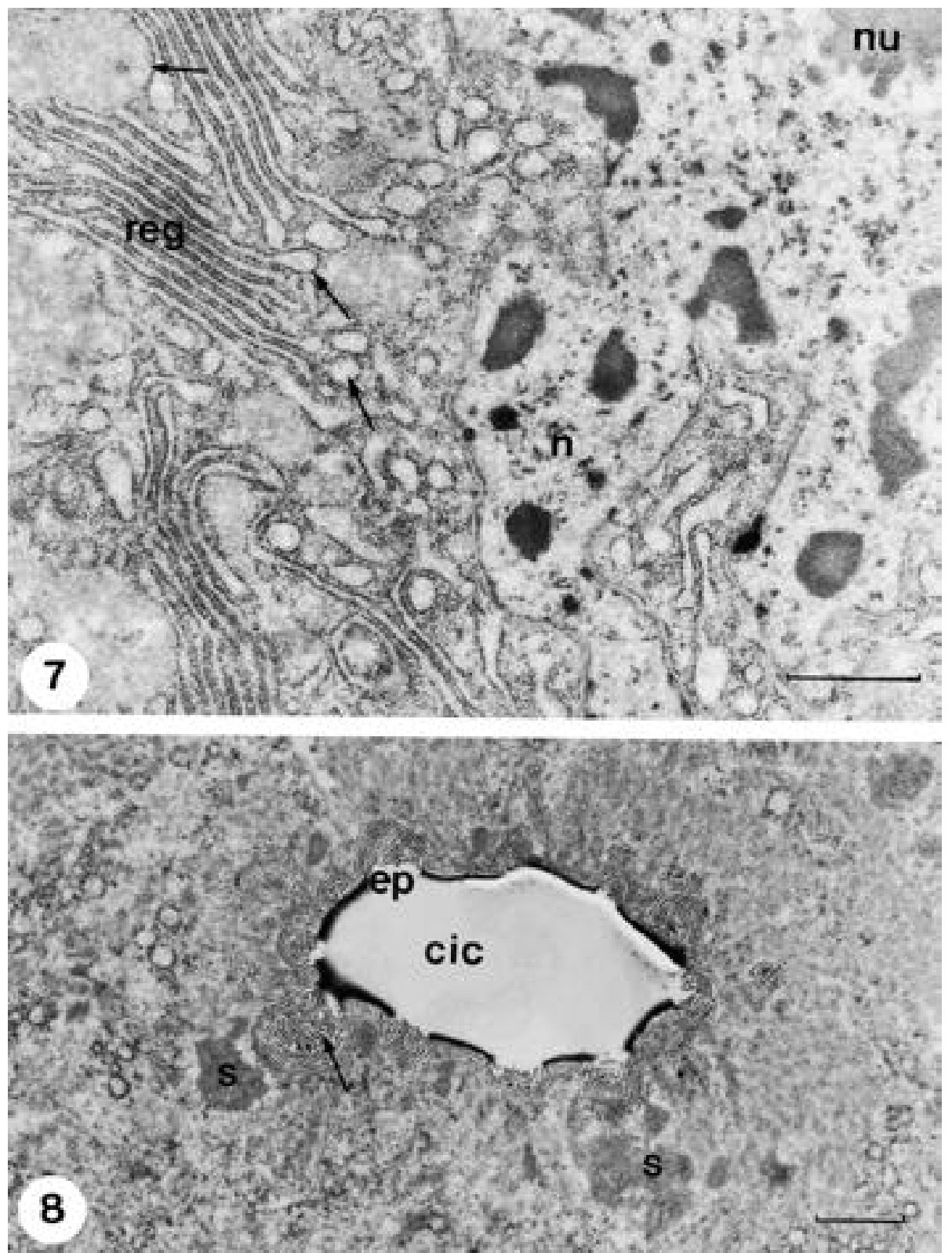

Figs. 7, 8. Oxaea flavescens, glândulas abdominais esternais (MET): 7, células glandulares, setas indicam as regiões dilatadas do retículo endoplasmático granular que formam as vesículas com secreção; 8 , canalículo intracelular, seta indica a epicutícula interrompida e porosa ao redor do canalículo (cic, canalículo intracelular; ep, epicutícula; n, núcleo irregular; nu, nucléolo; reg, retículo endoplasmático granular; s, vesículas contendo secreção). Escala, $1 \mu \mathrm{m}$.

Iheringia, Sér. Zool., Porto Alegre, 92(4):37-45, 30 de dezembro 2002 



Figs. 9, 10. Oxaea flavescens, glândulas abdominais esternais (MET): 9, lâmina basal; 10, regiões de Golgi (setas) (lb, lâmina basal; reg, retículo endoplasmático granular). Escala, $1 \mu \mathrm{m}$. 
conter vários nucléolos e grânulos de heterocromatina dispersos no nucleoplasma (figs. $4,7)$. Todas essas características indicam uma célula muito ativa, pois os contornos irregulares da membrana nuclear aumentam a superfície de trocas entre o núcleo e o citoplasma.

A porção intracelular dos canalículos percorre todo o interior da célula glandular e é revestida por uma cutícula porosa, separada do citoplasma pela membrana plasmática da célula secretora. A membrana plasmática delimita ao redor dos canalículos intracelulares um espaço, o espaço secretor da célula, para o qual a secreção é eliminada antes de passar para a luz do canalículo. A membrana plasmática, que delimita este espaço, invagina-se formando um extenso labirinto para o interior do qual a parte porosa da cutícula pode ramificar-se (fig. 8) aumentando a superfície de eliminação da secreção. A porção extracelular do canalículo, o canal excretor da célula, é revestida por cutícula nãoporosa e perfura a íntima para liberar a secreção para o interior do reservatório.

A secreção, antes de ser eliminada para a luz do canalículo intracelular, acumula-se ao redor do espaço secretor e no seu interior, após cruzar a membrana plasmática, o que sugere que, em algum momento, as vesículas, de aspecto floculento e média densidade, devem migrar para essa região e liberar seu conteúdo. A secreção nessa região já não se encontra no interior das vesículas e apresenta-se mais eletrondensa (fig. 8). A secreção passa para o interior do canalículo atravessando a cutícula porosa.

Uma possível composição muco-protéica encontra respaldo nos resultados de GuERINO \& CRUZ-LANDIM, 1999. A presença de material impregnado pelo vermelho de rutênio na superfície da célula (fig. 9) indica a possibilidade de carboidratos estarem sendo absorvidos da hemolinfa, os quais devem, então, entrar na composição da secreção, complexando-se com as proteínas.

As mitocôndrias são poucas e pequenas nas células secretoras. Regiões de complexo de Golgi, que deveriam ser bem desenvolvidas em células que produzem este tipo de secreção, não foram detectadas com as preparações de rotina. Contudo, a técnica do ósmio oxidado possibilitou a visualização de múltiplas regiões impregnadas (fig. 10) nos intervalos entre as ilhas de retículo granular, justamente onde se acumula secreção. Como freqüentemente nos insetos, o complexo de Golgi não apresenta a morfologia típica encontrada nos vertebrados, admite-se que nessas regiões estejam presentes Golgi atípicos.

A secreção produzida por estas glândulas, ao que tudo indica, não é volátil, sendo de natureza mucoprotéica ou glicoprotéica o que, comprometeria a função como feromônio do tipo desencadeador, com ação através do sistema nervoso. Poderia ser um feromônio do tipo modulador que ao ser ingerido atuaria através do sistema endócrino (KARLSON \& LÜSCHER, 1959). A localização das glândulas parece não favorecer este tipo de atuação.

Várias espécies de abelhas que constroem ninhos em cavidades no solo, o revestem com secreção glandular impermeabilizante. Uma possibilidade seria que, em Oxaea flavescens, a secreção tivesse esta função. MichENER (2000) assinalou que esta espécie reveste seus ninhos com material ceroso, o que não condiz com o retículo endoplasmático granular muito desenvolvido apresentado pelas células, nem com o aspecto da secreção, nem com suas propriedades tintoriais (GUERINO \& CRUZ-Landim, 1999). A presença destas glândulas, com grau de desenvolvimento bem maior do que o encontrado em glândulas correspondentes de outras espécies, inclusive da mesma subfamília, indica que tem grande importância, embora sua função permaneça desconhecida.

Iheringia, Sér. Zool., Porto Alegre, 92(4):37-45, 30 de dezembro 2002 


\section{REFERÊNCIAS BIBLIOGRÁFICAS}

Blum, M. S. \& Brand, J. N. 1972. Social insect pheromones: their chemistry and function. Am. Zool., Thousand Oaks, 12:553-576.

CRuz-Landim, C. 1963. Evolution of the wax and scent glands in the Apidae (Hymenoptera, Apidae) JI N. Y. Ent. Soc., New York, 71:2-13.

1996. Glândulas tegumentares abdominais de abelhas; ocorrência e ultra-estrutura. In: ENCONTRO Sobre Abelhas, 20, Ribeirão Preto. Anais... v.1, p.67-77.

Guerino, A. C. \& Cruz-Landim, C. 1999. A new type of sternal gland present in Oxaea flavescens (Hymenoptera, Oxaeinae): location and histology. Cytobios, Cambridge, 97:71-77.

Karlson, P. \& LÜscher, M. 1959. "Pheromones": a new term for a class of biologically active substances. Nature, London, 183:55-56.

Michener, C. D. 2000. The bees of the world. Baltimore, The Johns Hopkins University. 913p.

Noirot, C. \& Quennedey, A. 1991. Glands, glands cells, glandular units: some comments on terminology and classification. Annls Soc. ent. Fr., Paris, 27:123-128.

Snodgrass, R. 1956. Anatomy of the honey bee. Ithaca, Comstock. 344p.

Velthuis, H. H. W. 1970. Queen substance from the abdomen of honey bee queen. Z. vergl. Physiol., Utrecht, 70:210-222.

Wilson, E. 1963. Pheromones. Am. Sci., New Haven, 208:100-114.

Recebido em 10.10.2001; aceito em 28.08.2002

Iheringia, Sér. Zool., Porto Alegre, 92(4):37-45, 30 de dezembro 2002 